\title{
Supporting Digital Scholarship in Research Libraries: Scalability and Sustainability
}

Jennifer Vinopal, Librarian for Digital Scholarship Initiatives, New York University, vinopal@nyu.edu

Monica McCormick, Program Officer for Digital Scholarly Publishing, New York University, monica.mccormick@nyu.edu

\section{NOTES}

This is the peer-reviewed version of an article published in the Journal of Library Administration, 53(1), 2013, special issue "Digital Humanities in Libraries: New Models for Scholarly Engagement."

This version of the work is licensed under a Creative Commons Attribution-NonCommercial 3.0 Unported License.

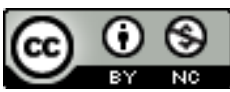

Issue URL: http://www.tandfonline.com/toc/wjla20/53/1

Article URL: http://dx.doi.org/10.1080/01930826.2013.756689

\section{Recommended Citation}

Vinopal, Jennifer, and Monica McCormick. "Supporting Digital Scholarship in Research Libraries: Scalability and Sustainability." Journal of Library Administration 53, no. 1 (January 1, 2013): 27-42. doi:10.1080/01930826.2013.756689.

\section{Keywords}

digital scholarship, digital humanities, library services, leadership, organizational culture, scalability and sustainability

\begin{abstract}
New York University Libraries and our partners in Information Technology Services offer effective enterprise-wide technology solutions for many academic practices, but we are still working to solve the "faculty website problem"--providing services for digital scholarship and publishing in a way that is both scalable and sustainable. This article describes our study of NYU scholars' needs and digital scholarship support at other research institutions, and then introduces a service model we developed for supporting such services (which may include digitization, hosting of research data, digital publishing, the development of software for scholarly practices, and more). We then discuss the
\end{abstract}


challenges to research libraries of implementing our service model in a scalable, sustainable way, by addressing project and tool selection, staffing, and organizational change. 


\section{INTRODUCTION: THE FACULTY WEBSITE PROBLEM}

At New York University, as at other large research institutions, we are working hard to support faculty and students who increasingly expect sophisticated new services for digital scholarship. ${ }^{1}$ NYU Libraries, with our colleagues in Academic Technology Services (ATS, a unit of NYU Information Technology Services), offer tools and support teams for activities including high performance computing; geographic information systems; quantitative and qualitative data analysis; data finding and management; the digitization, creation, manipulation, storage, and sharing of media content; repository services; digital preservation; streaming media platforms; digital journal publishing; online collaboration; and intellectual property consultation. These are enterprise-level services, offered to as many members of the NYU community as possible.

Despite this breadth of services and expertise, we find ourselves challenged to respond effectively to what we have come to call "the faculty website problem"--an ever-growing number of requests for web-based spaces and tools to collaborate on scholarly research and share the results. Despite the fact that scholars often describe their needs with the catch-all term "website," such requests actually represent a diverse set of activities which may be achieved in a variety of ways: with a wiki or basic blog, with more complex tools like a custom-designed database with public or private web access, with tools for collaboration with colleagues at NYU and beyond, integration with platforms elsewhere, or some combination of all of these. Support for these projects can be equally varied, and may require anything from a single consultation about available enterprise-level tools, to semester-long training and advice for a course's student projects, or an open ended commitment to implement a new tool or manage a scholarly digital collection.

Over the years we have approached these needs in several ways. In the late 1990s and early 2000s, Academic Technology Services had small, discipline-focused computing groups who supported specialized faculty projects in the humanities, arts, social sciences, and sciences. Because of the idiosyncratic nature of faculty projects, the significant time required to plan and accomplish their long-term research initiatives, and the need for ongoing care, development, and migration of resulting websites and databases, these computing groups could only support a few faculty per year. In the mid-2000s, in an effort to provide technology services to more users, NYU Libraries and ATS jointly committed to offering enterprise-level academic tools (e.g., wikis, blogs, streaming services, file storage, repository services) and correspondingly robust support services for the widest array of faculty and students.

\footnotetext{
${ }^{1}$ We follow the Scholarly Communication Institute's definition of digital scholarship as "the use of digital evidence and method, digital authoring, digital publishing, digital curation and preservation, and digital use and reuse of scholarship." Smith Rumsey, Abby. 2011. Scholarly Communication Institute 9: New-Model Scholarly Communication: Road Map for Change. Charlottesville, VA: University of Virginia Library. http://www.uvasci.org/wp-content/uploads/2011/04/SCl9-report.pdf.
} 
While emphasizing commodity tools and services has allowed us to provide a broad clientele with relatively easy-to-use solutions for many digital research needs, this standardization has come at the expense of supporting the kinds of innovative, web-based collaboration, communication, and publication activities that are becoming a regular part of scholarly practice across the disciplines at NYU and beyond. ${ }^{2}$ Current areas of scholarly exploration include the use and development of new tools and methods for multimodal and collaborative publishing (e.g., Scalar and MediaCommons ${ }^{3}$ ), open peer review (e.g., MediaCommons Press ${ }^{4}$ ), and data analysis and visualization (e.g., topic modeling, mapping and timeline tools). So far, our work in these areas is in early development.

To continue developing services that respond to changing scholarly practice, Dean of Libraries Carol Mandel asked us in April 2011 to better define NYU scholars' needs, to investigate how other universities, especially their research libraries, are supporting new web-based forms of collaboration, communication, and publishing, and to then propose a service model that might be adopted at NYU Libraries. We conducted research from April through November 2011, and submitted a report in December 2011. In this article we describe our findings and offer a high-level model for deploying scalable and sustainable digital scholarship services. ${ }^{5}$ We then discuss some important institutional and organizational challenges to research libraries and offer recommendations for providing effective digital scholarship support.

\section{GATHERING DATA}

\section{NYU Scholars' Needs}

To learn more about NYU scholars' needs (including both faculty and graduate students), we partnered with subject specialists to identify and interview eleven NYU faculty who are experimenting with technology for their research and publishing. We also

\footnotetext{
${ }^{2}$ NYU's Digital Library Technology Services has developed tools and platforms relevant to digital scholarship (e.g., MediaCommons, a network and publishing platform for scholars in media studies,

http://mediacommons.futureofthebook.org/) but the DLTS group's primary focus is on processing, enabling access to, and preserving digital materials from the NYU community and collaborating partner organizations.

${ }^{3}$ Scalar, in beta development by the Alliance for Networking Visual Culture, is an open source authoring and publishing platform that's designed to make it easy for authors to write long-form, born-digital scholarship online. Scalar enables users to assemble media from multiple sources and juxtapose them with their own writing in a variety of ways, with minimal technical expertise required. See $\underline{\mathrm{http}}$ ://scalar.usc.edu/scalar

${ }^{4}$ MediaCommons Press is part of the MediaCommons scholarly network. It uses the tool CommentPress (built on WordPress) to enable open online peer review. See http://mediacommons.futureofthebook.org/mcpress/

${ }^{5}$ Services are sustainable when they can be efficiently maintained over time, and scalable when they can be provided effectively as demand increases.
} 
performed a service gap analysis by reviewing recent technology support requests from scholars that we were either unable or only partially able to meet. Both sources of data revealed similar faculty needs and gaps in available services and resources. Scholars want help developing, using, and maintaining websites for storing and presenting their digital research content. Research may be used in various ways online: as a personal archive, to collaborate with students or colleagues, or to publish these materials via the web. Scholar requests for custom-built databases with web-searchable front ends indicate a need for interoperable tools and repositories that allow scholars to create, store, and work with materials in various formats (multimedia, images, text, annotation, etc.) and then provide easy online access to these materials. They want these sites to be dynamic (to add new content and functionality as needed) and to facilitate collaboration with colleagues. Faculty also need help for themselves and their students to learn new skills, methods, and tools, and they want support integrating them into their work.

\section{Interviews with Peer Institutions}

To understand how our peers support digital scholarship, we interviewed colleagues at fourteen institutions, ${ }^{6}$ focusing our questions mainly on services for online publishing and scholarly collaboration. We also asked about staffing, service location within the organization, and scalability and sustainability concerns. We discussed the same issues at conferences with colleagues from many other libraries. Among great variation in the tools, services, and staffing models our peers offer, we identified three basic approaches. All institutions we interviewed provide some version of these general types:

\section{Digitizing Collections: Infrastructure for Digitization, Preservation, and Access}

These services are driven primarily by library collections and focus on building infrastructure and workflows that may also be used for scholars' projects or shared with other parts of the library, making efficient use of staff time and equipment. Project selection can be closely aligned with library strategic priorities, user demand, or other criteria. However, these services do not address scholars' needs for the kinds of collaborative, multimodal digital services listed above.

\section{Digital Research \& Publishing services}

With a focus on scalability, these services support a wide range of needs with a small amount of customization and are typically available to most scholars. Examples include journal and conference paper hosting; institutional repositories; consultation on project planning, metadata, and digitization best practices; video and audio production; blogging, wiki, and content management platforms with a fixed set of templates and standard plug-ins for simple website creation; copyright and IP consultation. Many tools

\footnotetext{
${ }^{6}$ California State University, Los Angeles; Columbia University; Cornell University; Duke University; Emory University; Harvard University; Princeton University; University of California, Los Angeles; University of Chicago; University of Kansas; University of Michigan; University of Virginia; Yale University; and the Educopia Institute.
} 
can be provided with minimal training to users and without ongoing intervention by the service team. Related reference-type consultations are handled on a regular basis. While requests for customized services cannot typically be accommodated, service teams may consider strategically undertaking a special project if it is likely to result in a first-of-a-kind, rather than one-of-a-kind ${ }^{7}$, solution, which might eventually be rolled out more widely.

\section{Digital Scholarship or Digital Humanities Centers}

These centers are scholar-driven with a strong research and development component and may not be affiliated with the library. They include high-touch collaborations among scholars for a limited number of projects per semester or year. Scholars and staff on project teams are true research partners in this model, and staff may also pursue research projects on their own. Such projects may result in tools or platforms that can be reused in other settings (for example, the open source library discovery interface Blacklight ${ }^{8}$, which grew out of a staff project at the University of Virginia's Scholars' Lab). But because of the tight integration between a scholar's research methodology and its expression in digital form, the products may sometimes be idiosyncratic and thus hard to maintain over time without ongoing developer intervention.

No single service model mentioned here fully describes any of the organizations we spoke to, but we found it helpful to characterize services in these ways as the models suggest quite different approaches, staffing levels, and required skills. Furthermore, none of our colleagues felt confident that they had solved the problem of providing services for the breadth of digital scholarship needs in a way that was both sustainable and scalable. Like most of our peer institutions, NYU Libraries currently provides some services from each of these general types.

\section{A HIGH-LEVEL MODEL FOR SCALABLE AND SUSTAINABLE SERVICES}

Drawing on our understanding of practices and trends at peer institutions and our own faculty's research and requests, we developed a high-level model to describe how an organization might support digital scholarship. We had several guiding principles in designing this 4-tier model. Services should be sustainable (so they can be maintained over time) and scalable (in order to benefit as many scholars as possible). Our experience suggests, and peer interviews confirmed, that one effective way to achieve scalability and sustainability is through service and tool standardization. There are other considerations-programmatic and strategic requirements-as we discuss in the next section. As well, these services should promote the development of reusable tools,

\footnotetext{
${ }^{7}$ Thanks to Rebecca Kennison of Columbia University for this useful distinction.

${ }^{8}$ http://projectblacklight.org/
} 
platforms, and methods, and facilitate the creation of preservable, reusable scholarly content to ensure the long-term value of and access to the institution's research. This multi-level service model puts a strong emphasis on developing, maintaining, and integrating standard tools, platforms, and support services for a large community of users. The model should integrate current services and initiatives, and build out new service components only when necessary. Finally, these services should capitalize on staff knowledge and expertise, while providing an opportunity for staff to gain new skills.

The model we envisioned has four tiers, with the first (and most widely-used) at the bottom.

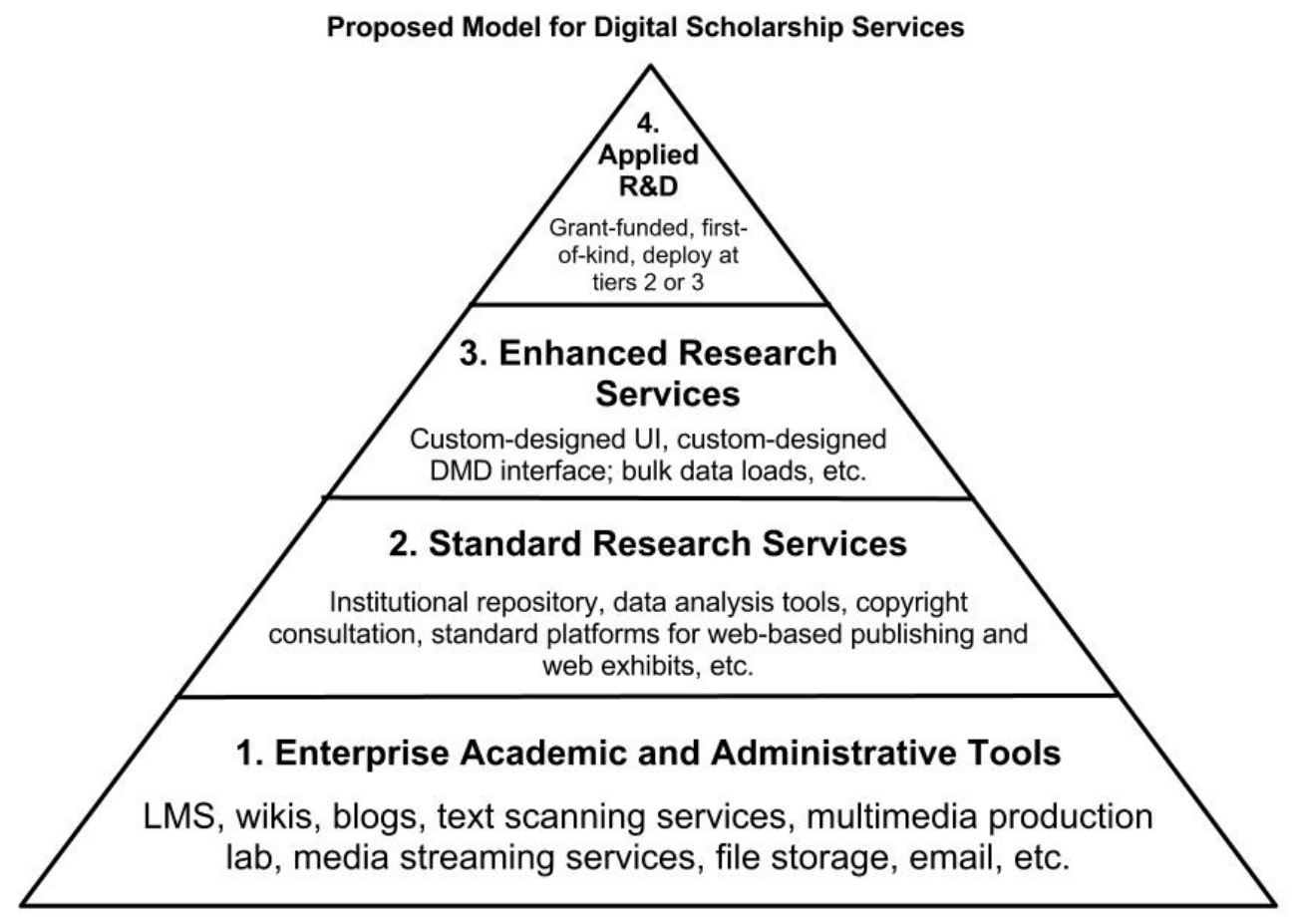

Tier 1: Enterprise Academic Tools

These are enterprise-level academic tools that meet the basic computing needs of a vast majority of students and faculty. Examples include: learning management systems, wikis, video streaming, individual and shared file storage, and virtual computer labs. These tools are designed to meet academic and administrative computing needs, but do not necessarily lend themselves to scholars' research requirements. Most offer little to no customization for individual projects.

\section{Tier 2: Standard Research Services}

Like the enterprise academic and administrative tools in Tier 1, these services are designed to be available to as many scholars as possible. However, tools at this service 
level are designed specifically to support research and scholarship. Examples include: journal and conference-paper hosting tools (e.g., Open Journal Systems or BePress), CMS and web-hosting platforms (e.g., WordPress), and web exhibit platforms (e.g., Omeka). ${ }^{9}$ Though certain tools or platforms may enable a large number of configuration choices, this service level does not offer that option. Rather, to the extent possible, tools should offer a fixed set of templates, so users can pick the format, style, or functionality that best meets their needs. For example, an institution-wide WordPress service could give users the choice of a limited number of design templates and approved plug-ins. If services at this level are well designed and supported, a majority of scholars could rely on these sustainable alternatives to one-off solutions.

\section{Tier 3: Enhanced Research Services}

This level builds on Tier 2 and includes the ability to offer some custom configuration of the standard services described there. Tier 3 provides select scholars with staff support for more sustained consultation and customization that go beyond the standard services and templates. Services might include designing a special interface to a standard tool or providing custom-tailored metadata options for a repository. In addition, this level could include short or long-term project consultations with scholars on project planning, grant seeking, or digital methodologies. Services in Tier 3 could lead to more in-depth partnerships at service Tier 4. Though the goal will always be to help as many scholars as possible, access to Tier 3 services, requiring more staff time and support, will be necessarily selective and a well-defined selection process is required to manage demand. Selection processes for these services will vary from institution to institution; criteria can range from focusing on VIP faculty, to partnering with a particular department or program, only accepting projects that come with grant funding, or offering funds for which scholars may compete. Whatever selection process is chosen, it needs to be well understood by staff and potential project partners so decisions demonstrate a strategic approach to services.

\section{Tier 4: Applied Research and Development}

This level is more experimental and aimed at developing methods and infrastructure with possible (but not certain) future research value. The focus is on partnership with innovative scholars, ideally leading to reusable products or integration among existing tools. A key objective is to create "first-of-a-kind" tools, platforms, methods, or integrations that meet emerging research needs, and to implement them in a cycle that supports use, testing, and improvement. Ultimately, the goal is to enable such services, methods, or tools to be rolled out as Tier 2 or Tier 3 services. Work in Tier 4 is highly selective, mostly grant-funded, and extremely staff intensive.

This tiered model provides a way for organizations to recognize their existing and

\footnotetext{
${ }^{9}$ These services complement existing library research services such as subject specialist research assistance, the library catalog, etc.
} 
desired services as a spectrum of methods for supporting digital scholarship, ranging from enterprise-level tools to experimental, resource-intensive initiatives. Articulating how the institution's services fall into the four tiers will help library staff and leadership consider the organization's strengths, gaps, and research needs, and determine how to best invest time and effort to strategically develop new services. In the next section, we address some challenges of implementing this model.

\section{CONSIDERATIONS FOR IMPLEMENTATION}

This high-level service model is not prescriptive; it can be applied in a variety of ways, depending on the given organizational context and structure. We believe it could be implemented with many different initiatives, tools, or services to achieve the desired level of engagement and support. Similarly, it can rely on a wide range of possible staffing arrangements. In planning to offer services for digital scholarship, institutions must be guided by local considerations such as user needs, strategic priorities, and existing organizational structures and services.

However, in order to implement scalable and sustainable services, there are certain programmatic and strategic requirements without which these initiatives may fail. 10 Scholars' needs for digital scholarship support are inherently diverse; in attempting to meet them without considering scale and sustainability, we risk developing narrowly focused or short-lived solutions that are difficult to maintain over time and with infrastructure that cannot be repurposed to benefit other projects. None of the peers we consulted have fully solved this problem, but they shared many helpful approaches. We are giving their ideas considerable thought as we develop and refine our own services. In this final section, we describe some of the most significant challenges to scalability and sustainability and propose some methods for addressing them.

\section{Selection and Scoping}

Though we talk about them as related goals, scalability and sustainability should also be considered individually when evaluating service options. There are times when one may be a more important consideration than the other. For instance, a valuable

\footnotetext{
${ }^{10}$ This past summer, Miriam Posner, The Library Loon, and Mike Furlough, among others, had a thoughtful discussion via their blogs about the institutional challenges to supporting digital humanities in the library. (Miriam Posner expands her original blog post as an article in this issue). They identified common impediments that cause incipient digital humanities services in libraries to falter and scholars and staff to become frustrated with the services offered. Their insightful observations complement the implementation considerations we derived from our research in 2011 and our subsequent work in this area. Posner, "What are some challenges to doing DH in the library?" retrieved from http://miriamposner.com/blog/?p=1274; Library Loon, "Additional hurdles to novel library services," retrieved from http://gavialib.com/2012/08/additional-hurdles-to-novel-library-services/; Furlough, "Some institutional challenges to supporting $\mathrm{DH}$ in the library," retrieved from http://www.personal.psu.edu/mif25/blogs/on furlough/2012/08/some-institutional-challenges-to-supporting-dh-in-the-lib rary.html
} 
service might be sustainable at a given staffing level, but not scalable to a larger clientele without adding significantly more resources or using a different technology. To get the most out of institutional investment in new initiatives, it's important to identify the intended audience, define the scalability and sustainability goals, and select tools, services, and projects strategically to meet these goals. For services intended to be scalable, our model advocates offering tools that offer a limited range of alternative interfaces and functionality but can be run and supported efficiently and thus offered to a large number of users (see Tier 2 in our proposed service model above). The City University of New York, for example, is developing the Commons in a Box, a content management system for blogging and collaboration, with a set of design templates and plug-ins for different needs. ${ }^{11}$ Columbia's Center for Digital Research and Scholarship offers a standard software platform and a tiered service model for journal publishing, with the basic service available at no charge and customization options provided for a fee. ${ }^{12}$ Such approaches provide useful alternatives for patrons, while building in constraints (templates, fee structures) that ensure the service can be supported with the resources available.

Once a tool or platform is selected for implementation, service definitions are critical to setting user and staff expectations for their use. According to the ITIL (IT Infrastructure Library) ${ }^{13}$ service management framework, a service definition or Service Level Agreement (SLA) typically specifies details of service hours and availability, functionality, service and customer support levels, customer and service provider obligations, as well as any associated fees. ${ }^{14}$ SLAs should also help staff and scholars understand the differences among services. For example, a training service should clearly state when and how training may occur, who is served, and what level of training is to be expected. And training to use tools must be clearly distinguished from, say, engaging in a long-term project with a scholar. When services are well defined and understood by all involved, it is easier to carefully assess the needs of a potential scholarly project and determine whether it can be met with an existing service (Tier 2 in

\footnotetext{
${ }^{11}$ Commons in a Box is described as, "a new open-source project that will help other organizations quickly and easily install and customize their own Commons platforms."

http://news.commons.gc.cuny.edu/2011/11/22/the-cuny-academic-commons-announces-the-commons-in-a-box-projec t/

12 The CDRS tiers of journal service are described at http://cdrs.columbia.edu/cdrsmain/texture-publications/which-service-level-is-right-for-my-journal/ More information about their journal services may be downloaded from http://cdrs.columbia.edu/cdrsmain/texture-publications/

${ }^{13}$ For more information about the IT Infrastructure Library (ITIL) see http://www.itil-officialsite.com/AboutITIL/WhatisITIL.aspx

${ }^{14}$ Service Level Agreements are defined here: http://www.knowledgetransfer.net/dictionary/ITIL/en/Service Level Agreement.htm
} 
our model) or if it requires consideration as a special project (Tiers 3 or 4). The traditional reference interview process provides an excellent model for these types of evaluations. For instance, a faculty member approached us about a "digital humanities project" that amounted to the need for a wiki where documents could be shared with students--a request easily met with a service already in place that could support the project as it evolved. More complex projects require a more substantial investigation before they can be selected, and will rely on the staff member who is conducting the initial interview to know where to refer the patron, or being empowered to assemble a team to discuss the request.

Having a well-developed project selection process allows organizations to make informed choices about how to strategically deploy staff on more experimental initiatives. Portfolio management--the process of documenting and assessing both projects and the services within an organization--provides a broad overview of the organization's work and enables service gap analysis, resource allocation, and project selection, and can thus facilitate strategic alignment. (Vinopal, 2012) We believe that project selection should be undertaken as part of an active portfolio management process to ensure scalability and sustainability. All projects in Tier 3 must, by definition, be selected, since those services cannot be offered widely. And for Tier 4, an organization may want to leverage its project selection process to identify "stretch" projects that will help it explore new areas and develop new capacities that may eventually benefit many other scholars. To ensure the return on resource investment, these "first-of-a-kind" projects must be selected strategically to fill in known gaps in the service portfolio. Success with this approach requires that decision makers: 1) understand the organization's service portfolio and service gaps; 2) have articulated the strategic priorities of the organization, in order to develop services that meet those goals; and 3) have a well-understood decision making process for selecting initiatives, assigning resources, and moving new projects forward. Some of those we interviewed have a regular meeting at which projects are assessed for their fit with organizational goals, skills, and staff time. Others assemble project assessment teams ad-hoc as requests arrive. However, without clear selection criteria, an overview of the project and service portfolio, and a strong understanding of project needs, this ad hoc method can result in a bulging portfolio and difficulties completing work on schedule. Once projects are selected, many institutions develop written agreements with project partners to clarify responsibilities and define project scope. These agreements are similar in some ways to SLAs, described above, but focus on the specific project rather than a broad service. Project agreements may stipulate the length of time any resulting systems (e.g., a specially-designed website) will be supported, by whom, and what kind of ongoing support is to be expected (for example, bug fixes only, ongoing development of new functionality, platform and content migration, etc.).

\section{Situating Services and Staffing}

Our research indicated that services supporting digital scholarship can be positioned within the library in any number of ways: they might be established as a 
separate, new unit or department; fully integrated into the existing organization, with staff members from many departments spending some of their time on digital services; or managed in a hybrid approach, with a small core staff who draw support from subject specialists, metadata experts, etc., on an ad hoc basis, depending on project need. Sometimes grant funding is used to hire staff for initial projects, with positions evolving into permanent lines as need is demonstrated and budgets allow. All of these approaches have implications for service sustainability and scalability.

No matter how these services are configured within the library, it is important that they eventually become an integral part of the holistic service environment of the organization. In their report "New Roles for New Times: Digital Curation for Preservation," Walters and Skinner emphasize the library-wide transformation required to build what they call "the trio of strong infrastructures, content, and services" to support digital scholarship. (2011)

While launching digital scholarship services as a separate unit or department with dedicated (and possibly new) staff may afford the unit flexibility and speed to develop quickly, consideration should be given to the relationship between that unit and the rest of the organization. If the eventual goal is to foster a new level of organization-wide engagement with emerging research practices and needs, then incubating new services among a small group can potentially limit the development and contributions of other staff. As a consequence, when service needs grow, it may be challenging for staff outside the new unit to support the services in an integrated way.

On the other hand, a staffing approach that will rely from the start on the participation of the whole organization may create problems of dilution and diffusion. Scattering responsibility for the initiative across the organization can inhibit focus and may also negatively affect staff participation, especially so if this work is in addition to staff's responsibilities for existing services. As well, library-wide staffing for new services would require a very clear message about priorities and goals for the organization, the departments, and the individuals involved, addressing questions such as: How do the new services build on existing work? What new skills are staff expected to acquire? What current work may become a lower priority? And, who has the authority to delegate this new work to staff across various departments? This last question is particularly important, as existing reporting structures can prove particularly resistant to cross-departmental collaboration. This amount of organizational change requires significant time, which might hinder an effective digital scholarship presence on campus.

A third option is a hybrid model that falls somewhere between the "separate unit" and the "fully integrated" approaches described above. One way to implement this model is to identify current staff who are best situated (because of knowledge and skills) to help develop digital scholarship services, then free them up to lead the initiative, without necessarily creating a new unit. The organization could then incorporate other staff or 
hire new staff strategically and incrementally as service direction and definition are established. These efforts could be supported by ad hoc reliance on subject specialists, archivists, metadata experts and others as needed, with more staff being trained and brought in to the services as time goes on. According to a survey of ARL libraries conducted in 2011, this provisional model is common among libraries developing support for digital humanities. (Bryson, et al., 2011) Our research suggests that it applies to general digital scholarship services as well. This incremental approach to staffing and service development has advantages, in that it can respond flexibly to fast-developing needs. Being small and somewhat apart from the existing organization during start-up phase, service providers can take a more exploratory, experimental approach to their work and then bring their experiences and conclusions back to the organization for larger-scale implementation. For example, staff may spend time developing strategic partnerships or running small test projects to learn what works and what does not. During the initial phase of service design, it is especially important to assess work being done and to use these early experiments and experiences to document needs and the resources required to meet them. Assessment activities can include: determining success criteria, evaluating client satisfaction, identifying what did and didn't work, calculating staff hours spent on development and support activities, estimating costs and possible efficiencies, and considering next steps. It is equally important to share these assessments at the appropriate level of detail with the rest of the staff, so that experience and learning are shared, and the services' evolution is understood.

While effective in a time of rapid change in service needs and financial constraints, ad hoc service provision should be seen as a tactic on the way to a longer-term strategy for robust and scalable service design and support. The authors of the ARL Digital Humanities survey note, "as demand for services supporting the digital humanities has grown, libraries have begun to re-evaluate their provisional service and staffing models. Many respondents expressed a desire to implement practices, policies, and procedures that would allow them to cope with increases in demand for services." (Bryson, et al., 2011) Scaling up these services and keeping them going over time can be challenging for staff. Like the "fully integrated" approach above, this hybrid model requires clear direction from library leadership about expectations and priorities; otherwise those assigned to initiate these services may have difficulty summoning the project and service support from colleagues who are already fully occupied with their own work. Additionally, if services in this area rely primarily on fellowship- or grant-funded staff, it can be very challenging to sustain them once staff leave or funds are spent.

\section{Funding}

Like the other service support considerations discussed above, funding approaches for digital scholarship services are diverse, including hard funding, fees for some or all services, and internal or external grant funding. Special funds are frequently required for projects and services that are offered in Tiers 3 and 4, since these are more staff-intensive and may require advanced technology skills. Some institutions require 
scholars who are proposing projects to come with grant money in hand. Others partner with scholars to help them secure funding. Another model is for those providing digital scholarship services (e.g., a digital scholarship center) to receive institutional funds that they then award as grants to researchers through a competitive project selection process. As with service definitions and project selection criteria, funding models should be well defined and clearly understood by all involved.

\section{Strategic Vision}

Noting how innovative digital initiatives and services successfully develop at some institutions and not at others, a colleague of ours has asked: "What can you do if my library director gets it and yours doesn't?" This simple question cuts to the heart of the matter: grassroots innovation and a few enterprising, proactive staff are no substitute for library leadership providing sustained vision, guidance, and support for these new initiatives. The scalability and sustainability of library initiatives depend not only on careful choices about technology deployment, well-developed service descriptions, and effective project selection and portfolio management, but also on staff having a clear understanding of how and why they are investing their time and talent in complex new services.

It is critical to identify strategic priorities that align with the larger institution's mission and goals, and to clearly articulate what the organization will and will not focus on. With such an array of options (tools, services, platforms, service models) no organization can undertake them all. Library leaders need to select organizational priorities, make them known, and fund them. Without focus, nascent efforts can become muddled and ineffectual. To foster cross-library engagement with this new service domain, leadership should ensure that it is understood across the organization as a strategic priority, and create a shared vision of how these new services relate to the library's mission and goals and can be effectively integrated with existing ones. It is also important to frankly acknowledge the challenges of providing stable ongoing services while remaining responsive to emerging needs. Implementing project and portfolio management to document and track the organization's services and projects can help to guard against taking on more work than can be accomplished at any one time.

\section{Authority and Time to Accomplish}

The staff who are specifically engaged in developing services for digital scholarship have particular needs arising from the way these services are situated within the organization. For a start, it is critical to identify staff with the appropriate knowledge and skills, and to give them the time to explore digital scholarship needs and establish the appropriate services. In addition, they must be provided with sufficient professional development support to maintain currency with rapidly evolving technology and standards. Furthermore, as we have said, because digital services necessarily rely on a wide range of expertise, staffing for them is frequently ad hoc in nature. A common 
scenario is for projects to be managed by a digital services person with project support staff who all report to others. As a result, those charged with creating digital scholarship services often have considerable responsibility to accomplish initiatives without the authority to mobilize the resources needed to succeed. This is the particular challenge that evolves from building services that are not housed in a traditional department or unit but instead are more interstitial and rely on cross-organizational support for staffing.

It is critical that new service managers have the authority to accomplish their work within the scope of the vision and direction that leadership sets out. Given the inherently ambiguous nature of new service requirements, digital scholarship service leaders need the authority to make decisions, to direct the work of involved staff, and to establish a process for decision-making and communication about priorities up and down the hierarchy. Everybody involved in these ventures, even in an ad-hoc capacity, needs to understand his or her role and responsibility in the project or service's success. Because the implementation of innovative new services requires a concomitant change in organizational mindset and practice, higher-level administration may need to intervene when work "gets stuck." It is not enough for library administration to remind department managers or their staff about organizational priorities in the abstract; they must recognize the time required for this work and help staff set priorities and allocate enough time to participate in this new initiative.

\section{Guidance}

Establishing new ventures requires even more guidance and feedback from leadership than maintaining existing services. Those developing new digital scholarship initiatives will need a process for regularly communicating with library leadership about progress and priorities, and for seeking direction at critical junctures. Implementing our tiered services model, for instance, will require a selection process for projects at Tiers 3 and 4, which are more staff-intensive. As well, goals with clear measures of progress and success should be established, so that projects and services can be regularly assessed, and changes implemented as needed. The steering process can take many forms, including regular meetings with a designated steering committee or ad hoc meetings with the library director or other appropriate manager. No matter what process is enacted, it should be clearly articulated, so there is no confusion about how and when staff should report, how much autonomy they have in decision-making, and when they should seek feedback. What is important is that everyone involved in the service development process, from top-level leadership down, should understand how the new service will be guided, how service priorities will be set, who makes which decisions, which success criteria and assessment measures will be used, and how questions will be answered when problems arise.

\section{CONCLUSION}


Over the course of this article we have highlighted challenges to and strategies for building scalable and sustainable digital scholarship services. More and more scholars want to adopt digital tools, platforms, and practices for research and teaching, and these technologies and methodologies evolve rapidly. As the nature of scholarship changes, research libraries' practices will also adapt in order to partner most effectively with scholars. New models for librarian-scholar collaboration include much more librarian engagement with the entire research process than ever before. From grant seeking, project planning, data collection and organization, and metadata creation, to data analysis and visualization, content dissemination, and long-term archiving, libraries have significant roles to play in developing and sustaining effective practices in digital scholarship.

The organizational challenges required for a research library to become and remain engaged with this quickly evolving scholarly landscape are not inconsequential. This requires not just a one-time organizational change, but also the development of an organizational culture that is inquisitive, adaptable, responsive, and that welcomes change, one that is willing to try new things, assess their success, and sometimes simply move on. As new opportunities, roles, and responsibilities emerge, library leadership must take an active role in articulating a strategic vision, defining priorities, addressing the connections between new services and established ones, facilitating horizontal as well as vertical communication and collaboration, and building a staff that are lifelong learners with evolving job descriptions. Our success in supporting new scholarly practices hinges on our ability to scale and sustain this kind of organizational change.

\section{REFERENCES}

Bryson, T., Posner, M., St. Pierre, A., \& Varner, S. (2011). Digital Humanities (No. 326). SPEC Kit (p. 192). Association of Research Libraries. Retrieved from http://www.arl.org/bm doc/spec-326-web.pdf

Vinopal, J. (2012). Project Portfolio Management for Academic Libraries: A Gentle Introduction. College \& Research Libraries, 73(4), 379-389. Retrieved from http://crl.acrl.org/content/73/4/379.full.pdf+html?sid=cde93e18-861b-4311-8cde-7ce4fc04 $\underline{131 \mathrm{e}}$

Walters, T., \& Skinner, K. (2011). New Roles for New Times: Digital Curation for Preservation. Washington, D.C.: Association of Research Libraries. Retrieved from http://www.arl.org/bm doc/nrnt digital curation17mar11.pdf 